\title{
Smart Energy meter using Power Factor Meter and Instrument Transformer
}

\author{
Subhashis Maitra \\ Kalyani Government Engineering College \\ Kalyani, Nadia, West Bengal, India
}

\begin{abstract}
Electric Supply office sends the consumption bill for the previous month depending on the consumption as indicated by the conventional electric meter placed in a domestic premises or business place. The consumer then going to the electricity office, stands in front of a long queue to pay the bill. This process is very much cumbersome and hazardous and also very cost effective both for the suppliers and the users. Advance researches on energy meter develop many new and cost efficient technologies to construct energy meter that help at the same time to improve the billing system as well as the payment system. In this paper, a new concept on energy meter has been explained using power factor meter and instrument transformer using embedded technology. The proposed energy meter is smart enough also for billing and payment system. This meter can automatically disconnect the power line with the meter circuit in the absence of any person in the room or in the office and thus is helpful in power saving. The proposed meter uses a pre-paid smart card. For the first time use, the consumer has to pay an amount according to the maximum demand and the smart card will be recharged accordingly. Then when the recharge value will be equal to the stop value, a warning is to be provided by the smart meter and the card is to be recharged again. The card may be recharged through net-banking, Davit/Credit card like all other rechargeable card.
\end{abstract}

\section{Keywords}

ARM Processor, Instrument Transformer, LVDT, Power Factor Meter, Recharged value, Smart card, Stop value, Thermocouple Type Instrument.

\section{INTRODUCTION}

Energy meter is a device that measures the amount of electrical energy consumed by a domestic consumer or a commercial consumer. There are basically two different types of energy meter, namely electromechanical type energy meter and electronic energy meter. Advance research on energy meter develop smart energy meter which is the modification of the basic two types. Electromechanical type basically includes induction type energy meter. Induction type energy meter [1][2] operates by counting the number of revolutions of a non-magnetic and conductive light metallic disc (Aluminum disc) which is made to rotate freely between two magnetic fields, which are proportional to the load voltage and load current and hence to the power passing through the meter. Here the driving torque is produced by the interaction between the magnetic fluxes produced by two electromagnetic coils namely pressure coil and the current coil. The pressure coil is connected in parallel whereas the current coil is connected in series with the load. Hence, the pressure coil generates a magnetic flux proportional to the load voltage and the current coil generates a flux proportional to load current. Hence the driving torque is proportional to the load voltage, load current and the power factor between them. Two major disadvantages of this type of meter are creeping error and phase angle error. Moreover the instrument is too heavy to carry. Due to change in supply frequency, it causes error. Friction also affects its readings. This type of meter is now nearly obsolete. On the other hand, electronic energy meter (EEM) [3][4] has no moving parts and its operation is based on digital micro technology. The various parts of this type of meter are potential transformer, current transformer, analog circuits, A/D converter, specially designed application specific integrated circuit operated on embedded technology and it controls the operations of the meter. The input sampled voltage is compared with a preprogrammed reference voltage. The output of the comparator is then converted to digital value using the A/D converter. The digital data is then converted into average value which is the measuring unit of power. The output of the application specific IC is available as pulses indicated by the LED placed in the front panel of the metering unit. The total number of pulses over a fixed time gives the average $\mathrm{KW}$ hour (KWH/Unit). One important advantage of EEM is its accuracy over nonlinear loads. Also the electronic measurement is more robust than that of the conventional mechanical induction type energy meters. Also it reduces the cost of energy theft and corruption of electricity distribution, improves the cost and electricity distribution system and finally measures current both in neutral and phase lines and then calculate the consumption of power based on the larger of these two values. This type of meter can support time-ofday billing. But it has no capability to disconnect the line automatically when the premises or business place are unmanned. On line billing and payment system are also not available in this meter. Other energy meters are smart energy meter [5][6], smart tri-vector meter [7][8]. Smart energy meter has stepper motor counter and LCD display whereas its accuracy lie between $0.2 \%$ to $0.4 \%$ and its minimum power consumption is $1 \mathrm{watt} / 4 \mathrm{VA}$. Smart tri-vector meter is a new generation of poly-phase fully programmable static meter with good billing and management applications from LV Industrial Consumers. .Smart Meters can measure register active, reactive and apparent power one by one or in combinations thereof. Communication facilities with GSM/ GPRS/PLCC/RF systems using RS232 bus, are the most advantageous features of this meter. The meters have separate Optical Port for local communication. It has additional memory storage capabilities for fast and reliable data transfer operation. Though these meter have greater accuracies but they are very expensive. Also automatic disconnection and billing/payment are not available in these metering systems. Kadu Rahul N. et. al in [9] discussed a new energy meter, known as "embedded energy meter" based on ARM technology. They claimed that the meter has high 
performance, low power consumption, design flexibility and scalability and optimum price. But this meter does not support online billing and payment system. Also there is no provision of high voltage security and automatic disconnection of power. Another energy meter discussed by Shraddha Male et. al. in [10], known as smart wireless electronic energy meter also based on embedded technology, has good coverage facility and manage fault tolerance. They claimed that the meter provides high level accuracy and security. But online recharge facility cannot be achieved using this meter. Also they did not mentioned about the cost and power consumption of the meter. In 2014, a new concept on energy meter [11] based on GSM technology has been invented by E. Moni Silviya et.al. This type energy meter uses mobile phone for instant billing. They claimed in their paper [11] that the cost efficient transmission of readings indicated by the energy meter ensures that the power consumption values can be transmitted more frequently to a remote station, i.e. electric supply office. But the power consumption of the meter does not fall into satisfactory limit. There are other energy meter like "prepaid billing energy meter" discussed by Richa Shrivastava et. al in [12], "An Advanced Smart Energy Metering System for Developing Countries based" discussed by Sai Kiran Ellenki et. al. in [13], "an intelligent energy metering using Zigbee and ARM 7" discussed by Mr. Sarwade Narasing J. in [14]. All these meter give accuracy, instant billing facilities, data transmission facilities to remote station. But these do not support online recharge facility, automatic disconnection of power due to the absence of the users or due to short circuit condition. The author of this paper has discussed another new concept of energy meter in [15]. The meter is based on embedded technology. The meter consists of smart card, terminal reader (TR) and an induction type energy meter with $\mathrm{F} / \mathrm{V}, \mathrm{A} / \mathrm{D}$ and some relays. The algorithm for designing the embedded meter has also been discussed here clearly. Though the meter discussed in [15], has better accuracy, automatic recharge facility of the smart card, automatic disconnection of the circuit in the absence of the user, the errors, like phase angle error and creeping error due to inserting the induction type energy meter cannot be eliminated. Here in this paper, a new concept of energy meter using instrument transformer and power factor meter has been discussed. The results using the proposed energy meter discussed here shows the novelty of the meter. A graphical comparison of the proposed meter with the conventional inductance type energy meter has also been dealt here clearly. A photographic view of the terminal reader using PIC microcontroller has been clearly demonstrated here.

\section{PROPOSED ENERGY METER}

The proposed energy meter consists of four parts, measurement section, controller section, terminal reader and smart card. The measurement section measure the energy consumed by the consumer in terms of the product of the load voltage, load current and the power factor of the load used. The controller section control the online billing and payment procedure and also it provides short circuit protection, automatic recharge, automatic disconnection of the line in absence of the user. Terminal reader verifies the authentication of the smart card and calculates the balance. Smart card, inserted in a slot provided in the terminal reader, is used to inform terminal reader about the recharge amount. The four sections are being discussed in the following.

\subsection{Measurement section}

Energy measurement section consists of an electrodynamometer type power factor meter (EDPFM), linear variable differential transformer (LVDT), potential transformer (PT), one current transformer (CT), analog-todigital converter (ADC), timer and relays. The connection diagram of the elements with a single phase line is shown in Fig. 1. As shown in the Figure, the phase line consists of the main switch and three normally close contacts (NC1, NC2 and NC3). These three contacts are operated by three electromagnetic relays (R1, R2 and R3) respectively. R1 is energized if there is no balance in the smart card, R2 is energized if the users are not present in the room and R3 is energized if any short circuit condition will occur. Timer (T) is used to count the time for which the load is taken into account in the circuit. This time is then multiplied with the reading of voltage, current and power factor to get the energy consumed. If no load is running, timer gives a stop pulse to the microcontroller. The current transformer used here steps down the line current through the load and then the voltage drop corresponding to the load current flowing through a standard resistance is digitized using ADC to send to the microcontroller. Similarly the potential transformer steps down the load voltage and then digitized using ADC to send to the microcontroller. Single phase power factor meter is an electro-dynamic type meter which measure the power factor of the load used in the circuit and gives a corresponding voltage through LVDT. The voltage is then digitized to send to the microcontroller. These three digital values are then multiplied with the time specified by the timer in the microcontroller unit and gives the corresponding energy consumed by the user.

Power factor meter circuit includes two coils namely pressure coil and current coil. Pressure coil is connected across the load while the current coil (fixed coil) is connected in series with the load. Pressure coil is splited into two parts known as purely inductive part and pure resistive part. The two parts are shown in the Figure 1 using the inductor (L) and resistor (R) respectively. No control system is included in the PF meter, since at equilibrium there exist two opposite types of forces which balance the movement of pointer. The reference plane (shown by the dotted line) makes an angle ' $\alpha$ ' with the coil 1 . Now the angle between the coils 1 and 2 is $90^{\circ}$. Hence the coil 2 makes an angle $\left(90^{\circ}+\alpha\right)$ with the reference plane. During measurement, the magnitudes of the impedance of both the coils are made equal in order they can carry equal magnitude of current. The phase difference between the two currents is $90^{\circ}$.

The equation of the deflecting torque in coil 1 is

$\mathrm{T}_{1}=$ KVIM $\quad \operatorname{Cos} \quad \alpha \quad$ Sin $\quad \beta$

(1)

Where $\mathrm{V}$ is the load voltage, $\mathrm{I}$ is the load current, $\mathrm{M}$ is the maximum value of the mutual inductance between the two coils, ' $\alpha$ ' is the angle of the reference plane with coil 1 and ' $\beta$ ' is the angular deflection of the plane of reference.

Similarly the deflecting torque for coil 2 is

$\mathrm{T}_{2}=\mathrm{KVIM} \operatorname{Cos}(90-\alpha) \operatorname{Sin}(90+\beta)=\mathrm{KVIM} \operatorname{Sin} \alpha \operatorname{Cos} \beta$ (2) 


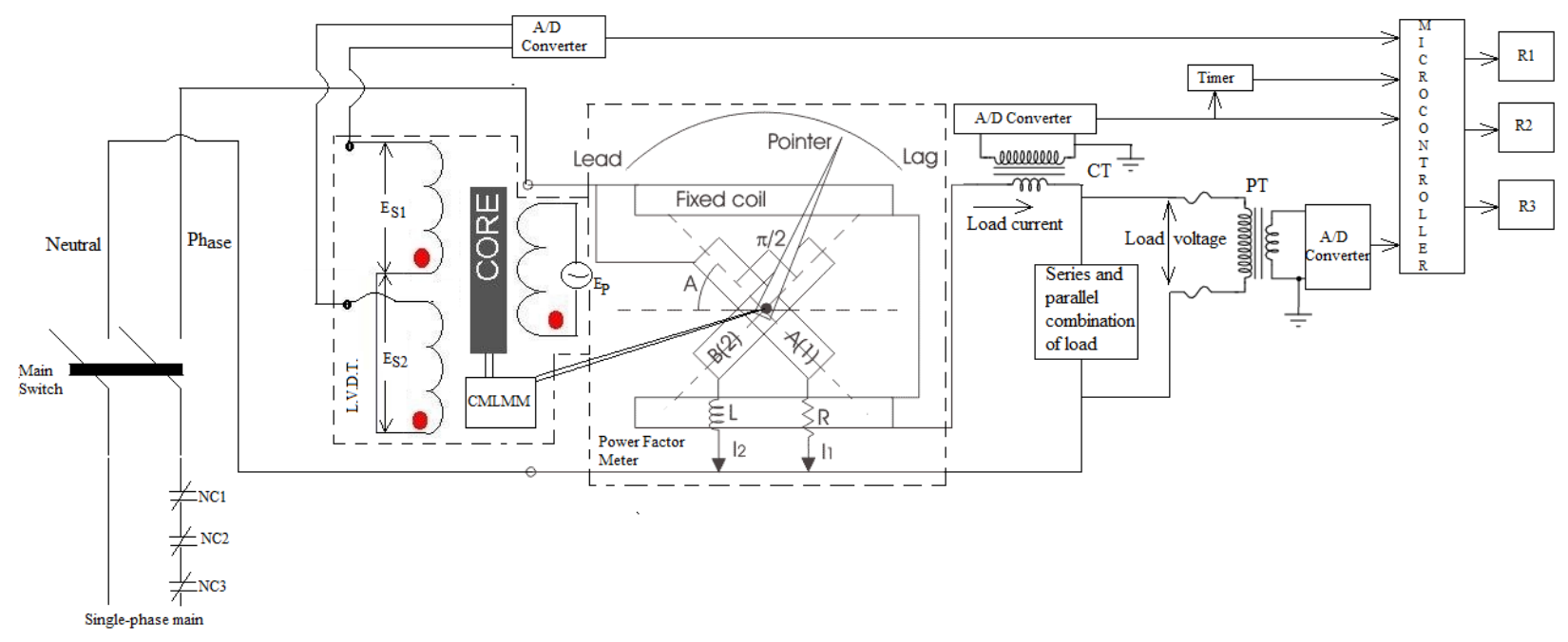

Fig. 1. Diagram of the proposed Energy meter.

At equilibrium both the torque are equal, i.e. $\mathrm{T}_{1}=\mathrm{T}_{2}$, hence $\alpha=\beta$. Now the 'cosine' of the angular deflection ' $\beta$ ' can be converted into linear displacement ' $x$ ' (say) by the circular motion - to - linear motion converter mechanism (CMLMM), i.e. $x=k_{1} \operatorname{Cos} \beta$, where ' $k_{1}$ ' is a factor, known as sensitivity factor and it depends on the CMLM conversion mechanism.

This linear motion ' $x$ ' is then converted into electrical signal using the LVDT. $\mathrm{E}_{\mathrm{P}}$ is the primary excitation voltage of the LVDT, whereas $E_{S 1}$ and $E_{S 2}$ are the differential secondary voltages. The output of the LVDT is $\mathrm{E}_{\mathrm{O}}=\mathrm{E}_{\mathrm{S} 1}-\mathrm{E}_{\mathrm{S} 2}$. Hence the output can be written as
$\mathrm{E}_{\mathrm{O}}=\mathrm{k}_{2}(\mathrm{x})$
$=\mathrm{k}_{1} \mathrm{k}_{2} \operatorname{Cos}$
$\beta=\mathrm{KCos}$
$\beta$ (3)

Where $\mathrm{K}=\left(\mathrm{k}_{1}\right) \mathrm{x}\left(\mathrm{k}_{2}\right)$ and $\mathrm{k}_{2}$ is another constant of proportionality. Thus the output of the LVDT is proportional to the power factor of the load. The output $\mathrm{E}_{O}$ is then measured using thermocouple type instrument and then converted to digital signal using ADC. The digital output corresponding to the power factor is then fed to the microcontroller.

The load current is step down to a lower value using the CT the output of which is measured with respect to a voltage across a standard resistance. The output is then converted to DC value using thermocouple type device. The DC voltage is then converted to digital signal and is fed to the microcontroller. The timer connected with the output of the ADC which when gives zero digital signal (i.e. when no load is connected), the timer gives a stop pulse to the microcontroller to stop energy calculation. The load voltage is similarly converted into digital signal using thermocouple type device and ADC and is fed to the microcontroller.

\subsection{Controller Section [16]}

The microcontroller then calculates the energy consumed by the user and check with the minimum balance of the smart card. If the energy consumed exceeds the minimum balance, the relay $\mathrm{R} 1$ is energized and the contact $\mathrm{NC} 1$ is disconnected and the phase line thus becomes isolated from the main switch. If any short circuit condition will take place, relay R3 will be energized and the contact NC3 will disconnect the phase from the main switch. Similarly the absence of the user in the room can be detected by CCTV like sensor and sends signal to the microcontroller which then energizes the relay $\mathrm{R} 2$ and disconnect the main from the phase. The block diagram of the microcontroller section is shown in Fig. 2.

In Fig. 2, the microcontroller is AVR which has four 8-bit input/output ports. Three of the input/output ports are used to take 8-bit current reading, 8-bit voltage reading and 8-bit power-factor reading. Port \# 4 are used both for input and output. Lower half of Port \# 4 is used as input whereas upper half is used as output. Four lower pins of Port \# 4 take the reading from infrared source and detector which indicates the presence or absence of the user in a room, minimum balance pulse from the smart card, short circuit pulse (SCP) if any short circuit condition will occur in the electrical circuit and timing pulse (TP) corresponds to a fixed time determined by the balance of the smart card. The pulse from the smart card is generated when the balance in the card equals minimum balance and thus the controller gives a time to recharge. The upper half of Port \# 4 gives the outputs for four relays. Relay \# 1 is used to disconnect the main if the balance in the card become half of the minimum balance. That is the card should be recharged when minimum balance will come otherwise the main will be disconnected. Relay \# 2 disconnects the main if no persons, indicated by the infrared source and detector, are present in the room. Relay \# 4 is used to disconnect the main if any short circuit condition will occur in the electrical network. The microcontroller has real time clock (RTC), watch dog timer (WDT), internal RAM, external RAM and EEPROM and a display unit to get the reading of the energy consumed for a particular period of time. The display unit also displays the current energy reading. The microcontroller calculates the energy consumed for a specific time using the equation shown below.

$\mathrm{E}=(($ current reading $) \mathrm{x}(\mathrm{CT}$ ratio $) \mathrm{x}($ voltage reading $) \mathrm{x}(\mathrm{PT}$ ratio $) \mathrm{x} \quad(\mathrm{PF} \quad$ reading $) \times \mathrm{T}) /\left(\mathrm{k}_{1}\right) \mathrm{x}\left(\mathrm{k}_{2}\right)$ (4)

Where, $\mathrm{k}_{1}=$ displacement/Power factor $=$ sensitivity factor of mechanical arrangement that converts power factor into its corresponding displacement

$\mathrm{k}_{2}=$ LVDT output/displacement $=$ sensitivity factor of the LVDT and $\mathrm{T}$ is the specific time. 


\subsection{Terminal Reader [17]}

It is also a controller based system that communicates between the main control section and the smart card. While the smart card placed in the slot provided in the terminal reader (TR), it sends a signal to the consumer to authenticate the smart card using the password provided by the Electric Supply Office. When the card is authenticated, TR gives the information about the name, address, pole number, consumer number of the consumer. It also provides the information about the balance in the card and also about the minimum balance. Minimum balance is required to get the time to recharge the card in order for continuation of the supply. TR gives the minimum balance information to the main controller through a pulse. The block diagram of the terminal reader is shown in Fig. 3. The different functional blocks of TR are PROM, ROM, RAM, Timing and Control unit, Processor unit, interfacing unit and display unit. The processor unit reads the data corresponding to the authentication password and match it with that stored in its ROM. It also reads the balance from the smart card and sends a control signal to the main control section corresponding to the minimum balance.

\subsection{Smart Card [17][18]}

It is just like a SIM card in mobile phone. It has also controller which controls the activity to recharge through mobile phone like device or through network. Electric supply office provides a password in the smart card during application of new connection. The password can be changed time to time for security purpose. The block diagram of the smart card is shown in Fig. 4. When the smart card is inserted into the slot of the TR, TR wants to know the authentication password and then checks with the prefixed value. The smart card used in this paper is shown in Fig. 5. When TR gets authentication password, it gets ready to be used.

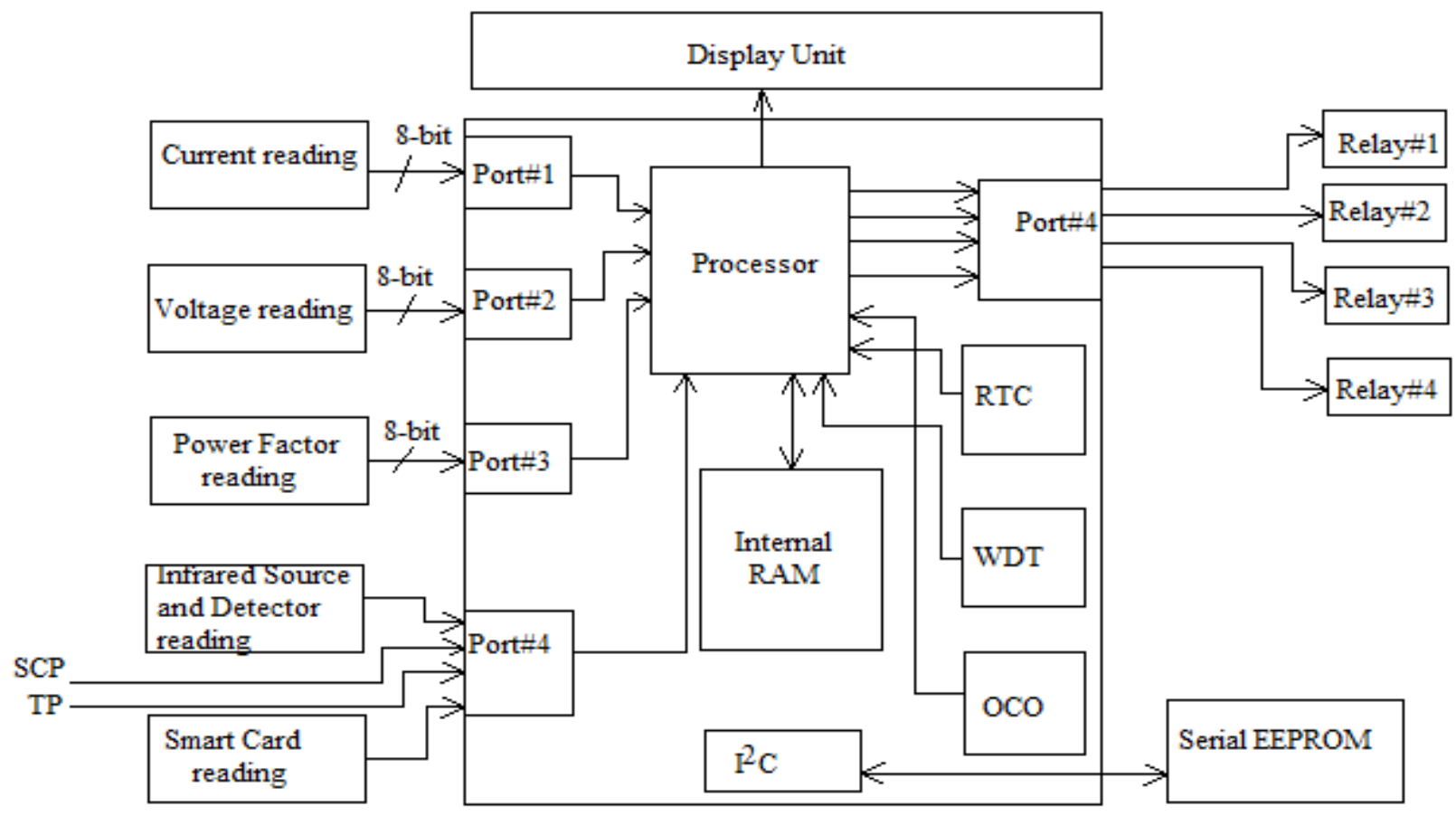

Fig. 2. Block Diagram of the microcontroller section.

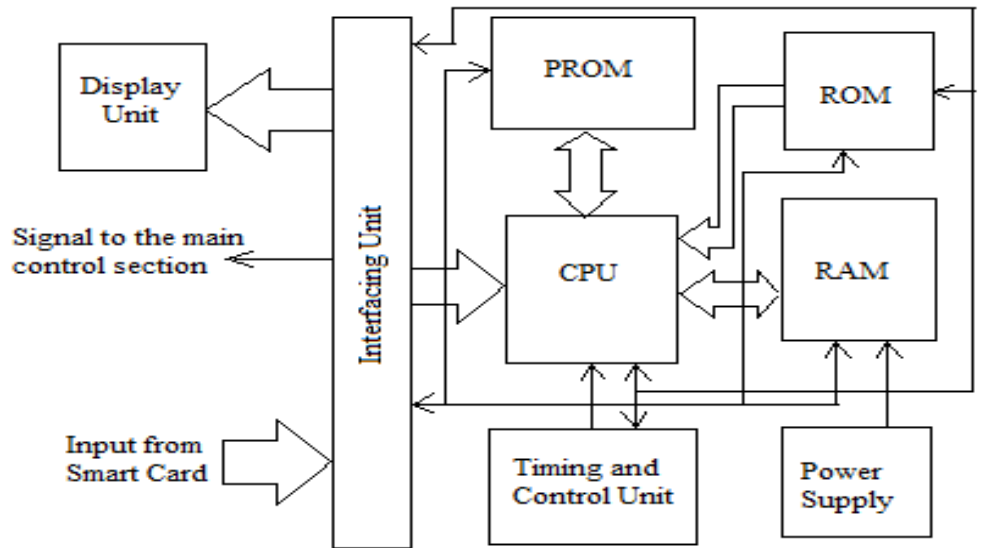

Fig. 3. Block diagram of Terminal Reader. 


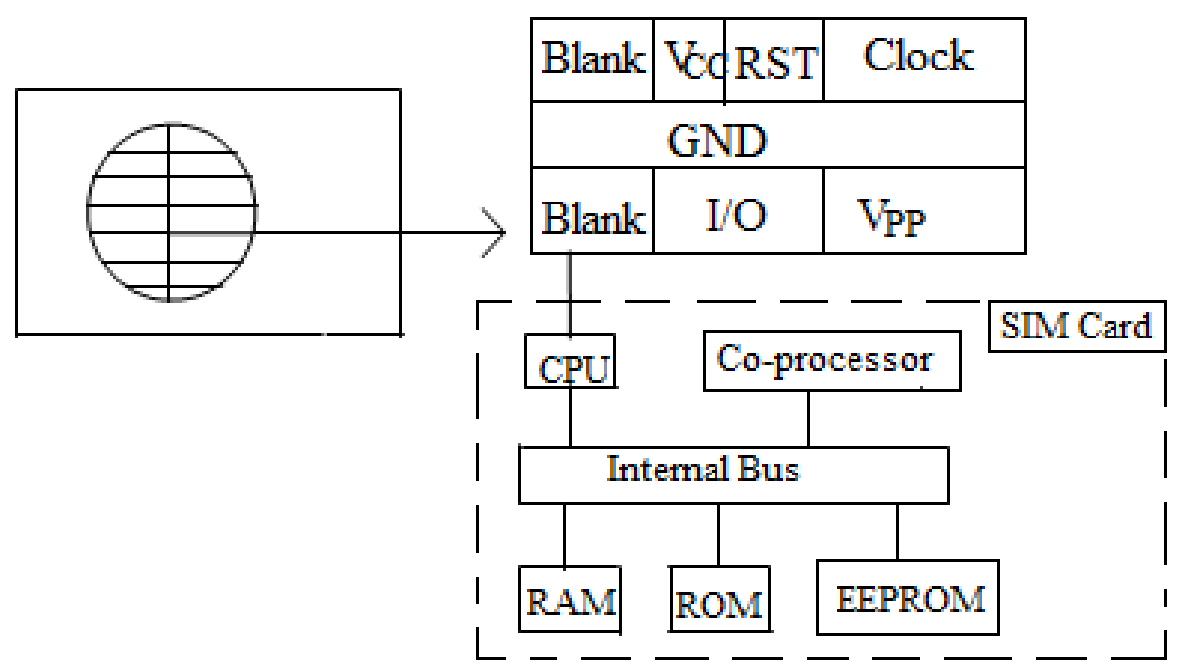

Fig. 4. Block Diagram of Smart Card.

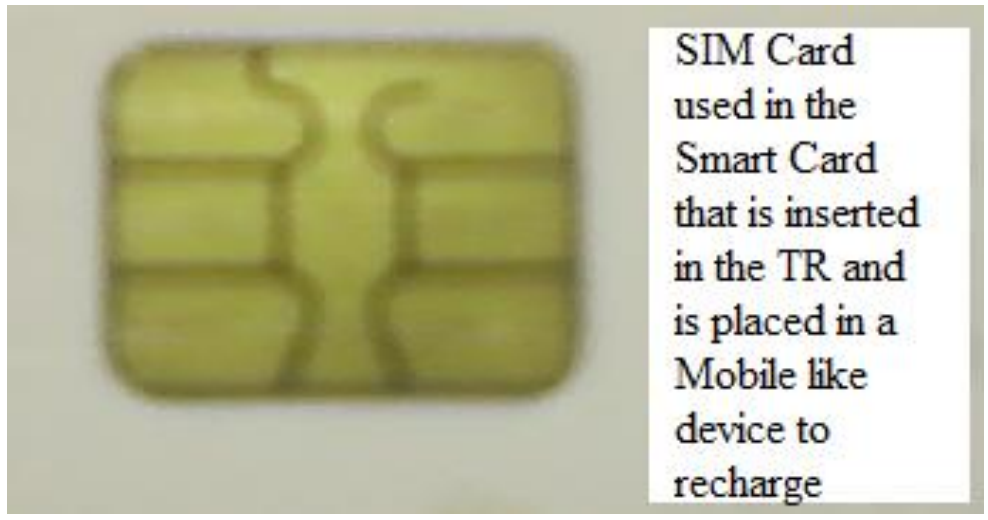

Fig. 5. Typical SIM Card used in Smart Card.

\section{EXPERIMENT AND RESULTS}

Experiment has been performed using the proposed energy meter with different types of loads such as electric fan, electric bulbs, electric heater etc. with the experiment setup as shown in Fig. 6. In Fig.6 a switch is used to connect different loads with the energy meter and main. Here five electrical appliances have been used to measure the energy consumed per hour. Two of the appliances are two electric bulbs of 100 Watt and 60 Watt respectively which are generally used as loads, one electric fan of 100 Watt, one electric heater of 1500 Watt and one electric pump (Sump) of 346 Watt. Each load are tested for one hour and the energy consumed by them are recorded by the proposed energy meter and are listed in Table 1. The specification of the CT, PT and LVDT used here are given below.

CT - Application standard - IEC/EN60044 - 1, rated primary rating $-1 \mathrm{~A}$ to $7500 \mathrm{~A}$ (set at $400 \mathrm{~A}$ ), rated secondary standard output $-5 \mathrm{~A}$, rated burden $-1,1.25$, $60,100 \mathrm{VA}$ made by Rishabh Instrument, transformation ratio (400/5). PT - Transformation ratio $33 \mathrm{KV} / 110 \mathrm{~V}$, rated output $30 \mathrm{VA}$, made by Rishabh Instrument.

LVDT - Input 3 to $15 \mathrm{~V}$ (r.m.s.), sine wave of $50 \mathrm{~Hz}$, stroke from $\pm 125 \mu \mathrm{m}$ to $75 \mathrm{~mm}$, sensitivity 0.6 to $30 \mathrm{mV}$ per $25 \mu \mathrm{m}$ under excitation voltge 3 to $6 \mathrm{~V}$. Here $\mathrm{k}_{1}$ and $\mathrm{k}_{2}$ are 0.005714 and 200 respectively.

From Table 1, it is clear that the proposed energy meter gives the accurate reading, where the accuracy is approximately \pm $0.35 \%$. The construction of the Terminal Reader using microcontroller trainer kit is shown in Fig. 7 and Fig. 8.

\section{CONCLUSION}

Since the proposed energy meter has no revolving part, it is free from creeping error. Also the proposed energy meter has no series and shunt magnet like other conventional energy meter and hence it is free from phase angle error. The energy meter has four main parts like measurement section, controller section, terminal reader and smart card. The controller section, the smart card and the terminal reader are constructed using PIC16F877A. The language used here is $\mathrm{C}^{++}$using KEIL software. The meter is password protected, short circuit protected. Online recharge facility of the smart card is also available in the proposed meter. The meter can be disconnected automatically if no person is present in the room. The additional benefits of this meter are its low cost, light, long life and flexible by changing the software used in the smart card, terminal reader and controller. 


\section{REFERENCES}

[1] Sawhney, A. K., "A Course in Electrical and Electronics Measurement and Instrumentation", Dhanpat Rai and Sons, eleventh edition, 1995.

[2] Raman, B., "Overview of Single Phase Induction Type Energy Meter", Technical Articles, Electrical Engineering Portal(EEP), September, 2012..

[3] Ashna, K., "GSM based automatic energy meter reading system with instant billing", IEEE International MultiConference on Automation, Computing, Communication, Control and Compressed Sensing (iMac4s), 2013, pp(s). 65 - 72, 22 - 23 March, 2013.

[4] Sehgal, V. K..; Panda, N.; Handa, N. R.; Naval, S. and Goel, V., "Electronic Energy Meter with Instant Billing", Fourth IEEE ULSim European Symposium on Computer Modeling and Simulation (EMS 2010), pp(s). 27 - 31, 17 - 19 November, 2010.

[5] Arif, A.; Al-Hussain, M.; Al-Multairi, N.; Al-Ammar, E.; Khan, Y. and Malik, N., "Experimental study and design of smart energy meter for the smart grid", IEEE sponsored International Renewable and Sustainable Energy Conference (IRSEC2013), pp(s). 515 -520, 7 - 9 March, 2013.

[6] Prudhvi, P.; Bhalodi, D.; Manohar, M.; Padidela, V. and Adapa, S., "A Smart energy Meter Architecture in Indian context", IEEE $2^{\text {nd }}$ Iranian Conference on Smart Grids (ICSG2012), pp(s). 1 - 6, 24 - 25 May, 2012.

[7] Xiao, P.; Venayagamoorthy, G.K. and Corzine, K.A., "Seven-Level Shunt Active Power Filter for High-Power Drive Systems", IEEE Transactions on Power Electronics, vol. 24, issue 1, pp(s). 6 -13, January, 2009.

[8] Mori, H.; Matsui, K.; Kondo, K.; Yamamoto, I. and Hasegawa, M. "Parallel-connected five-level PWM inverters", IEEE Trans. Power Electron., vol. 18, no. 1, pp.173 -179, 2003.

[9] Kadu Rahul, N.; Shaikh, S.A.; Turakne, S.S.; Taware, S.S. and Aher V.A., "An embedded electric meter based on ARM9 and zigbee technology", International Journal of Computer Technology and Electronics Engineering (IJCTEE), vol. 2, issue 2, pp(s). 121 -124, June, 2012.
[10] Male, S.; Vethekar, P.; More, K. and Bhusari, V.K., "A Smart Wireless Electronic Energy Meter Reading Using Embedded Technology", International Journal of Engineering Research and Applications, vol. 4, issue 1(version 3), pp(s). 145 - 147, January, 2014.

[11] Moni Silviya, E.; Meena Vinodhini, K. and Salai Thillai Thilagam, J., "GSM Based Automatic Energy Meter System with Instant Billing", International Journal of Advanced Research in Electrical, Electronics and Instrumentation Engineering, vol. 3, special issue 3, pp(s). 44 - 49, April, 2014.

[12] Shrivastava, R. and Mishra, N.K., "AN EMBEDDED SYSTEM FOR WIRELESS PREPAID BILLING OF DIGITAL ENERGY METER", International Journal of Advances in Electronics Engineering, vol. 1, issue 1, pp(s). $322-324$.

[13] Ellenki, S. K.; Srikanth Reddy, G. and Srikanth, Ch., "An Advanced Smart Energy Metering System for Developing Countries", International Journal Of Scientific Research and Education, vol. 2, issue 1, pp(s). $242-258,2014$.

[14] Sarwade Narasing, J.; Dehadray Bhushan, M.; Khedkar Sachin, T. and Turkane, S.S., "An Intelligent Energy Metering Using Zigbee and ARM 7", IOSR Journal of Electronics and Communication Engineering (IOSR JECE), vol. 9, issue 3, version 1, pp(s). 1 - 4, May June, 2014.

[15] Maitra, S., "Embedded Energy Meter- A New Concept To Measure The Energy Consumed By A Consumer And To Pay The Bill" Proceeding of Joint International Conference on Power system Technology and IEEE Power India Conference 2008 pp: 1-8.

[16] Ganurkar, S. and Gour, P., "Prepaid Energy Meter for Billing System Using Microcontroller and Recharge Card", International Journal Of Core Engineering and Management (IJCEM), vol. 1, issue 1, pp(s). 12-18, April, 2014.

[17] Mir, S.; Rufer., L. and Courtois, B., "On-chip testing of embedded transducers”, pp(s). 463-472.

[18] Theocharides, T.; Link, G.; Vijaykrishnan, N.; Irwin, M.J. and Wolf, W., "Embedded hardware face detection" , Proceedings $17^{\text {th }}$ International Conference on VLSI Design, 2004, pp(s). 133- 138.

\section{APPENDIX}

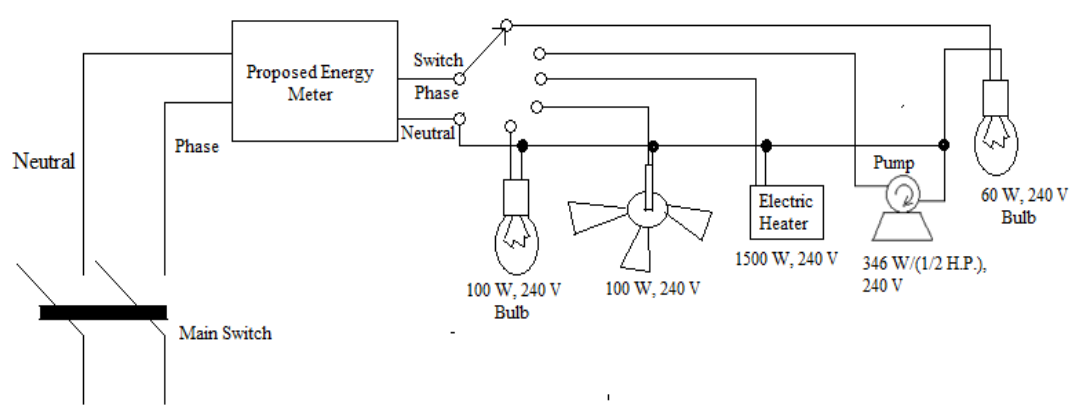


Fig. 6. Wiring diagram of the proposed energy meter with loads.

Table 1. Energy consumed by different loads per hour as calculated by the proposed energy meter

\begin{tabular}{|l|l|l|l|l|l|l|l|l|}
\hline Load & $\begin{array}{l}\text { P.T. } \\
\text { Output } \\
(\mathrm{V})\end{array}$ & $\begin{array}{l}\text { ADC(P.T.) } \\
\text { Output } \\
(\mathrm{V})\end{array}$ & $\begin{array}{l}\text { C.T. } \\
\text { Output } \\
(\mathrm{A})\end{array}$ & $\begin{array}{l}\text { ADC(C.T.) } \\
\text { Output } \\
(\mathrm{A})\end{array}$ & $\begin{array}{l}\text { P.F.M. } \\
\text { Output } \\
(\mathrm{mm})\end{array}$ & $\begin{array}{l}\text { LVDT } \\
\text { Output } \\
(\mathrm{mV})\end{array}$ & $\begin{array}{l}\text { ADC(LVDT) } \\
\text { Output } \\
(\mathrm{V})\end{array}$ & $\begin{array}{l}\text { Energy } \\
\text { consumed } \\
\text { per } \\
\text { hour WH }\end{array}$ \\
\hline $\begin{array}{l}\text { 100 Watt } \\
\text { Bulb }\end{array}$ & 0.8 & 0.7998 & 0.0074 & 0.007395 & 0.004 & 0.8 & 0.801 & 99.4931 \\
\hline $\begin{array}{l}60 \text { Watt } \\
\text { Bulb }\end{array}$ & 0.8 & 0.7998 & 0.0045 & 0.00446 & 0.004 & 0.8 & 0.802 & 60.08 \\
\hline $\begin{array}{l}\text { 100 Watt } \\
\text { Fan }\end{array}$ & 0.8 & 0.7998 & 0.00578 & 0.00577 & 0.00514 & 1.028 & 1.035 & 100.30 \\
\hline $\begin{array}{l}1500 \\
\text { Watt } \\
\text { Heater }\end{array}$ & 0.8 & 0.7998 & 0.0781 & 0.0782 & 0.00571 & 1.142 & 1.144 & 1502.6 \\
\hline $\begin{array}{l}346 \text { Watt } \\
\text { Pump }\end{array}$ & 0.8 & 0.7998 & 0.0305 & 0.03049 & 0.00337 & 0.674 & 0.678 & 347.22 \\
\hline
\end{tabular}

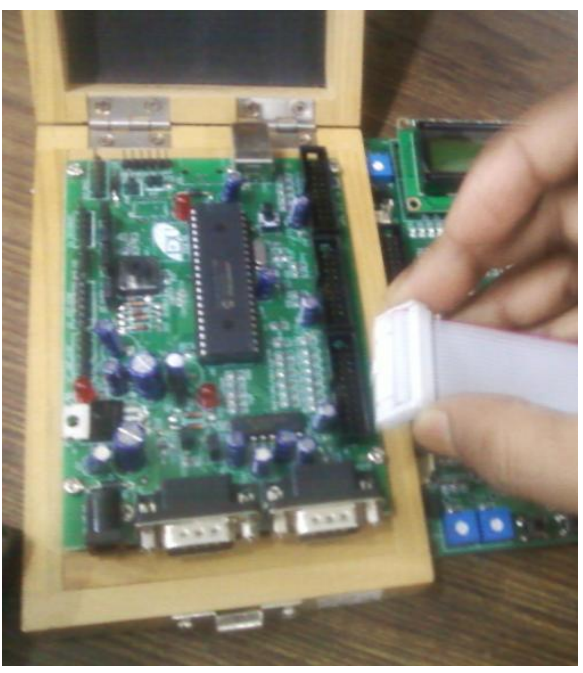

Fig. 7. Microcontroller training kit to design the Terminal Reader.

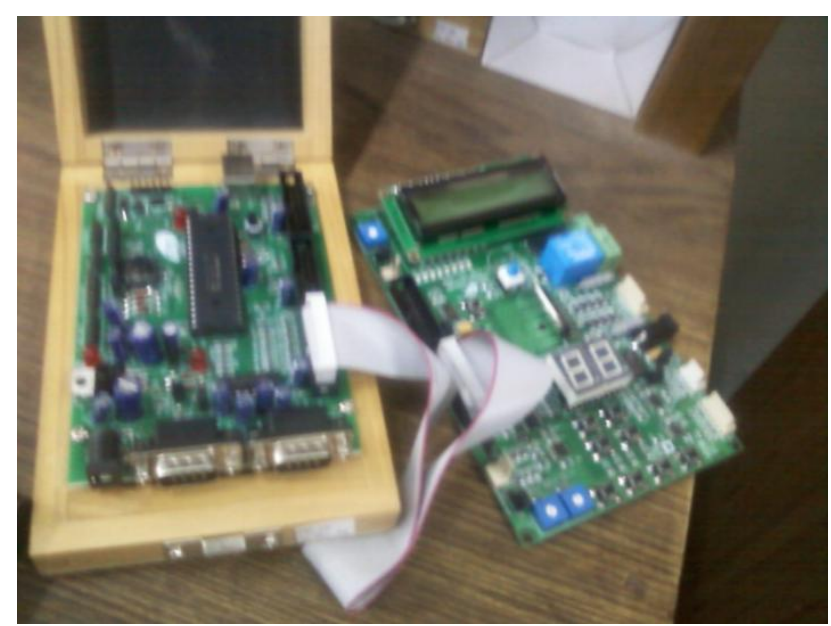

Fig. 8. Proposed Terminal Reader. 